\title{
Sobral, L.F. 2015. Bogart duplo de Bogart: pistas da persona cinematográfica de Humphrey Bogart, 1941-1946. São Paulo: Terceiro Nome (Coleção Antropologia Hoje). 152 pp.
}

\author{
DIOGO BARBOSA MACIEL
}

Mesmo na mais célebre cena de Humphrey Bogart no cinema, a despedida de Rick Blaine e Ilsa Lund nos minutos finais de Casablanca (1942), vem à tona o traço fundamental do que, em seu primeiro livro, Bogart duplo de Bogart - pistas da persona cinematográfica de Humphrey Bogart, 1941-1946, Luís Felipe Sobral identifica como a persona cinematográfica do ator: a "tensão violenta entre uma indiferença aparente e uma vulnerabilidade que irrompe repentinamente" (p.21). Nesse momento particular da performance de Bogart, tal característica adquire a forma de um discurso ao mesmo tempo lúcido e colérico através do qual impele a personagem de Ingrid Bergman a embarcar sem ele em um avião rumo a Lisboa. A convicção de Rick, no entanto, é interrompida por um instante de fragilidade, proveniente da lembrança de seu breve e intenso romance vivido na França anos antes, expresso de forma resignada na famosa frase we'll always have Paris (sempre teremos Paris) que, em contraste com as lágrimas de Ilsa, o mantém no controle da situação mesmo na iminência do sacrifício de seu amor.

Há pelo menos duas leituras possíveis, não excludentes, do ensaio de Sobral: a primeira dá a ver uma história do apogeu do sistema de estúdios de Hollywood em princípios dos anos 1940, quando se consolida uma forma específica de fazer filmes gestada desde a década de 1910. O texto acompanha a maneira como, nesse momento em particular, emergem como demandas no mercado de entretenimento norte-americano os temas relacionados à guerra, ao nazismo e ao exílio. A segunda possibilidade de leitura do ensaio se insinua através da construção da trajetória de Bogart como parte integrante dessa mesma história. A ênfase aqui recai na elaboração da persona cinematográfica do ator, baseada em um tipo particular de masculinidade no qual se concentra a força de sua atuação e sua marca distintiva enquanto intérprete. Sob a dupla constrição das transformações sociais em curso e do desenvolvimento do mercado cinematográfico, Bogart encena na tela, segundo o argumento de Sobral, uma "tecnologia de gênero" específica - conceito inspirado no trabalho de Teresa de Lauretis - que o cinema hollywoodiano ajuda a produzir e difundir.

Estudo de gênero e etnografia da história do cinema, assim, vêm articulados em uma narrativa cuidadosamente construída por Sobral, que costura em um texto rigoroso e de leitura agradável as relações que se estabelecem entre trajetória individual, experiência social e cultura visual. Fio condutor do livro, a noção de persona, segundo o autor, é construída ao longo de um determinado período, em uma 
equação complexa cujos fatores são de ordem social e artística, relacionados sempre ao aparato técnico-cinematográfico e às constrições advindas do momento histórico e do mercado de entretenimento (o tipo de filme em que cada estúdio preferencialmente investe, as demandas do público, as condições de produção etc.). Agindo fundamentalmente sobre a corporalidade dos intérpretes - e, no caso em questão, sobre sua performance de gênero - esses aspectos da persona marcam a atuação individual projetada na tela, e através deles os artistas se diferenciam e se alojam na estrutura cinematográfica, mantendo filme após filme as soluções cênicas encontradas para a construção dos personagens. Trata-se de uma noção apropriada, portanto, para articular uma ideia eficaz de masculinidade, projetada e difundida na tela, e o processo oculto de produção corporal, cinematográfica e social por meio da qual ela se manifesta.

A elaboração da persona de Bogart é identificada por Sobral já nas expectativas de seus pais para seus estudos universitários, passando pelo início de sua carreira como ator na Broadway e pelos seus primeiros papéis em personagens rasos - gângsteres, valentões etc. - até a guinada definitiva de sua carreira rumo ao estrelato nos estúdios da Warner em Hollywood na primeira metade dos anos 1940. Flagrante, mas ainda incompleta na cena final de Casablanca mencionada acima, ela começa efetivamente a se delinear, segundo o autor, com a elaboração dramática do detetive Sam Spade, primeiro protagonista encenado por Bogart, em O falcão maltês (1941).

É esse o filme que serve de motivo para a análise empreendida em "O beijo de Spade", capítulo de abertura e de maior fôlego do livro, cujo ponto de partida é a cena em que o detetive negocia seus serviços com a personagem Brigid O’Shaughnessy, típica femme fatale interpretada por Mary Astor. A descrição da cena do beijo de Spade e Brigid serve de disparador para uma reflexão sobre a descontinuidade entre a imagem visível na tela de cinema e o seu processo de produção, de onde deriva o desnível entre a trajetória social e a imagem do artista, relação resultante tanto da ascensão do sistema de estúdios quanto da estrutura narrativa própria do cinema hollywoodiano. Estes fatores, de acordo com Sobral, confluem e conformam uma primeira fase, anterior à guerra, da persona cinematográfica de Bogart, na medida em que o corpo do ator em $O$ falcão maltês concentra a elaboração da imagem do detetive durão e sensível, seguro de si apesar de súbitos de vulnerabilidade, e supera os personagens de pouca complexidade do início de sua carreira em Hollywood.

Spade foi fruto de um processo que fugia quase totalmente ao controle de Bogart. Baseado em As regras da arte de Pierre Bourdieu, Sobral argumenta que o ator teria até então apenas uma pequena margem de autonomia criativa na elaboração de seus personagens, constrangidos por vetores que, como dito, iam além de sua própria performance, passando pela lógica dos estúdios e pelas demandas do mercado cinematográfico. O falcão maltês deu ao ator, por um lado, maior controle sobre a produção de seus filmes, por conta do aumento de seu prestígio decorrente do sucesso da película, mas o deixou, por outro, mais dependente de características marcantes do personagem, na medida em que acarretou uma exigência externa de continuidade dramática em seus trabalhos posteriores. Isso significa dizer que, a partir de Sam Spade, Bogart passou a elaborar personagens semelhantes a partir de um eixo dado pela persona, ao qual se acrescentavam pequenas variações, ao passo que caracteres fundamentais eram mantidos e explorados comercialmente. 
Sobral empreende já no primeiro capítulo o procedimento analítico que vai se repetir na sequência de seu ensaio: a descrição do beijo de Spade em Brigid serve como um "indício" que suscita variadas linhas de investigação, opção que, na economia do livro, se configura em pequenas subseções consecutivas, cujos temas guardam, às vezes mais às vezes menos, relação com a anterior, sempre remetendo aos desdobramentos da cena inicial. Forma ao mesmo tempo de reflexão e de apresentação, o procedimento "detetivesco" é declaradamente inspirado no método indiciário de Carlo Ginzburg (p.74) - aliás, presente também na tese de doutorado de Luís Felipe Sobral sobre as representações da literatura e da antropologia parisienses sobre a corrida de touros espanhola - e mimetiza também o objetivo de $O$ falcão maltês, que "não é outro senão descrever o olhar do detetive" (p.61). Como consequência, talvez menos prevista, a forma expositiva flexibiliza um certo modelo de escrita e apresentação acadêmica algo gasto, abrindo caminho para modos criativos de narrar sem prejuízo do rigor da análise.

Embora o último diálogo de Casablanca, que abre este texto, tenha permanecido na história do cinema hollywoodiano, é outro encontro de Rick Blane e Ilsa Lund neste filme que serve de indício para o capítulo seguinte, "O triângulo amoroso". Novamente, trata-se de um momento em que o personagem de Bogart abandona a postura de homem durão, autoconfiante, e desaba diante de um beijo, agora de Ingrid Bergman. Não por acaso, a imbricação entre história pessoal e história coletiva (a interferência da guerra no amor de Rick e Ilsa) e a absorção do conflito global como tema privilegiado e condicionante externo para o fazer cinematográfico (por meio de censuras, indicações e restrições) são os principais temas do capítulo.

Inspirado nos vínculos entre cultura visual e experiência social, tais como sugeridos pelo método de análise de obras de arte proposto por Michael Baxandall, Sobral lê esta segunda etapa da elaboração da persona de Bogart a partir do "conjunto de possibilidades históricas específicas" (p.86) do momento. Rick Blaine não é mais o valentão de seus primeiros papéis e nem o detetive sagaz de O falcão maltês, e sim um tipo refinado, elegante e mundano, que "abre mão de seu interesse pessoal (o amor de Ilsa) pela defesa da [...] liberdade” (p.100). O autor constata que, mesmo a serviço do governo norte-americano, Hollywood manteve um espaço de autonomia em relação à sua própria produção, o que, todavia, não impediu a formação de um tipo como Rick Blaine, bem afeito, ainda segundo Sobral, à capacidade de representar os Estados Unidos detida pelo cinema (p.103).

A atriz Lauren Bacall adquire em "A caixa de fósforos”, uma centralidade quase similar à de Bogart. Não é para menos: esse capítulo final trata justamente do que, na visão de Sobral, era o elemento que faltava à composição final persona cinematográfica do ator: o par romântico. Tendo atuado juntos em À beira do abismo (1944) e Uma aventura na Martinica (1945), filmes que servem de base à análise, Bogart e Bacall foram elaborados não apenas na tela do cinema, mas sobretudo no material publicitário - pôsteres, trailers etc - que acompanhou a divulgação dos filmes. Sobral argumenta que esses materiais são baseados não nas características dos intérpretes, cujo perfil "não-artístico" é desenhado no capítulo por meio da recuperação suas trajetórias pessoais e sociais, e sim em suas respectivas personas. Segundo o argumento do livro, trata-se de um processo de divulgação que retoma "um conjunto de atributos associado a um personagem de um filme anterior e [o vincula] ao personagem do filme promovido" (p.123). Artista e personagem, assim, se confundem na percepção do espectador, uma vez 
que em lugar da elaboração de novas construções dramáticas, investe-se na associação publicitária a filmes anteriores e mesmo na adaptação de roteiros - como no caso de $\grave{A}$ beira do abismo - em função dos atributos peculiares das personas de ambos: a masculinidade pautada na indiferença aparente combinada a uma vulnerabilidade súbita, no caso de Bogart, e o olhar provocativo aliado à insolência, no caso de Bacall.

Chama atenção neste capítulo em particular - e no conjunto do livro de modo geral - a variedade e o apuro analítico com os materiais de pesquisa. São muitas as fontes mobilizadas pelo autor. Além dos quatro principais filmes do início da carreira de Bogart, O falcão maltês, Casablanca, À beira do abismo e Uma aventura na Martinica, a trajetória do ator e a história do cinema Hollywoodiano nos anos 1940 é contada através de pôsteres, trailers, das peças e romances que deram origem aos roteiros, de biografias e histórias do cinema etc., fontes tão bem selecionadas que a falta de imagens - ausentes no livro embora presentes na dissertação de mestrado que lhe deu origem - não chega a comprometer a leitura e os detalhes da análise.

Em resumo, a construção da persona de Bogart, de acordo com o argumento do livro, se baseia tanto no par performance corporal-trajetória social quanto no sistema de estúdios, nas constrições históricas e sociais que convergiram para sua transformação e no apogeu do mercado de entretenimento. Constrições das quais derivaram uma ideia bastante específica de masculinidade, presente no público privilegiado do cinema hollywoodiano ao mesmo tempo que forjada por essa mesma indústria, tal modelo se baseia na descontinuidade entre a imagem projetada na tela e o seu processo de produção. “Graça a esse procedimento", diz Heloísa Pontes no prefácio ao livro, "alcançamos não só a persona de Bogart como entendemos as condições sociais, as convenções cênicas e as tecnologias de gênero que a sustentaram em um momento bem delimitado da história do cinema norte-americano” (p.16).

Convite ao estudo das artes, do cinema especificamente, a partir de um viés antropológico e da temática de gênero, o livro de Sobral se pauta na reconstrução desse período da história do cinema norte-americano a partir de um viés interessado nos vínculos entre a trajetória social do ator e a ascensão de certa configuração particular da indústria cinematográfica. Exercício de recuo histórico, portanto, dedicado à análise cultural de feitio etnográfico, par metodológico que justifica as principais referências que servem de base à análise do autor, todas elas atuantes em fronteiras disciplinares: Carlos Ginzburg e Michael Baxandall principalmente, mas também Walter Benjamin e Pierre Bourdieu, oferecem suporte teórico para uma análise que, complexa por sua ambição, é bem sucedida porque parte de uma trajetória particular e vai além dela, mostrando como uma configuração particular da indústria cinematográfica contribuiu de maneira complexa para o prestígio de Bogart e para a difusão de um determinado modelo de masculinidade.

\section{Diogo Barbosa Maciel é mestre em Antropologia Social pela USP.}

RECEBIDO: 09/03/2017

APROVADO: 28/06/2017 